\title{
EDITORIAL
}

\section{Toward a life span developmental psychopathology perspective on bipolar disorder}

\author{
DAVID J. MIKLOWITZ ${ }^{a}$ AND DANTE CICCHETTI ${ }^{b}$ \\ ${ }^{a}$ University of Colorado; and ${ }^{b}$ University of Minnesota
}

Bipolar disorder (BD) is a chronic, recurrent disorder carrying high morbidity and mortality, leading to health costs of at least $\$ 45$ billion per year (Kleinman et al., 2003). It is the sixth leading cause of disability among all illnesses (Murray \& Lopez, 1996). Between 15 and $28 \%$ of bipolar adults experience illness onset before the age of 13 , and between 50 and $66 \%$ of them experience it before the age of 19 (Leverich et al., 2002, 2003; Perlis et al., 2004). The exact prevalence in children is unknown, but an estimated 420,0002,072,000 US children have the illness (Post $\&$ Kowatch, 2006). Persons with onset of BD in childhood or adolescence have a more severe, adverse, and continuously cycling course of illness than adults, often with a preponderance of mixed episodes, psychosis, suicidal ideation or behaviors, and multiple comorbidities (Geller et al., 2002). Without early intervention, early-onset $\mathrm{BD}$ patients can be derailed, sometimes irrevocably, in social,

Our work on this Special Issue and editorial was partially supported by grants from the National Institute of Drug Abuse, the National Institute of Mental Health, and the Spunk Fund, Inc.

Address correspondence and reprint requests to: David J. Miklowitz, Department of Psychology, University of Colorado, Boulder, CO 80309-0345, or Dante Cicchetti, Institute of Child Development and Department of Psychiatry, University of Minnesota, 51 East River Road, Minneapolis, MN 55455. neurobiological, cognitive, and emotional development (Miklowitz et al., 2004).

In the last decade, there has been a flurry of research targeting effective pharmacotherapies and psychotherapies to treat BD in children and adults. Much disagreement exists about the appropriate boundaries between pediatriconset $\mathrm{BD}$ and other childhood psychiatric disorders, the continuity between the pediatric, adolescent, and adult forms of the illness, the population prevalence of the childhood-onset forms, and the pharmacological strategies that are appropriate in younger age groups (Leibenluft, Charney, Towbin, Bhangoo, \& Pine, 2003; McClellan, 2005; NIMH, 2001). Fortunately, these disagreements have not stalled efforts to identify biological or psychological risk markers or to develop and test early intervention and prevention programs. Intervening early in the illness may prevent inappropriate interventions that may worsen or hasten the development of BD, delay the onset of a first manic episode, and/or prevent the development of full-blown $\mathrm{BD}$.

The purpose of this Special Issue is to acquaint readers with current thinking about the diagnosis, course, etiology, and pharmacological and psychosocial treatment of BD or its prodromal forms. We asked each set of authors to consider BD from a developmental psychopathology perspective: what do we know about how the symptoms of BD emerge 
over time, at different stages of development? How do these dynamic processes unfold in the context of other risk and protective factors? In what ways do traditional treatments (pharmacotherapy) and adjunctive treatments (psychosocial intervention) have to be modified to take into account age, developmental stage, and phase of the illness? What factors moderate responses to treatment, and what might be some of the mediating mechanisms by which treatments operate?

This Special Issue on BD is extremely important because it highlights the life span perspective embodied by the field of developmental psychopathology (Cicchetti, 1993, 2006). A developmental understanding of adaptation is not limited to childhood; rather, it cuts across all periods of the life course. Thus, this Special Issue attempts to get beyond the $D S M I V$ based view of BD as a category whose onset simply varies across the age span, to consider how bipolar symptoms emerge over time in the context of different risk and protective factors in the social, emotional, cognitive, or biological developmental domains (Cicchetti \& Rogosch, 2002; Cicchetti \& Toth, 1995; Miklowitz, 2004).

\section{Four Themes}

The first theme of the Special Issue is the attempt to describe and validate the bipolar diagnosis at different stages of development. Carlson and Meyer take a purely phenomenological approach to describing the disorder in school-aged children; likewise, Luby and Belden take on the controversy of describing and classifying preschool mania. There are considerable complexities to assessing the symptoms of pediatric BD and distinguishing it from near-neighbor conditions such as attention-deficit/hyperactivity disorder (ADHD). As Youngstrom, Meyers, Youngstrom, Calabrese, and Findling point out, reliable and valid interviews, checklists, and modern statistical methods (such as area under the curve analyses) have considerably advanced this nascent field.

A second theme is the course and prognosis of illness: how do these illnesses unfold over time, especially among children whose symptoms fall short of the fully syndromal condition? Birmaher and Axelson report the findings of their innovative longitudinal study of bipolar I, bipolar II, and bipolar not otherwise specified disorder among children and teenagers. They find that a considerable number of children "convert" from prodromal forms of the disorder to the full syndrome in relatively short intervals ( 84 weeks). The outcome of these disorders is sobering: most bipolar children are at high risk for suicide, poor functioning, and end up treated with multiple medications.

Tillman and Geller report the surprising finding that children with ADHD are at relatively high risk $(28.5 \%)$ for switching to prepubertal or early adolescent BD over a 6-year period. It would appear that ADHD is a risk factor for $\mathrm{BD}$, especially when there is a family history of affective disorder.

The bulk of this Special Issue focuses on a third theme: the interactive roles of psychobiological vulnerability and stress in the onset and course of BD. Alloy, Abramson, Walshaw, Keyser, and King discuss dysregulation in the behavioral approach and inhibition systems, both of which require psychosocial triggers for mood symptoms to become manifest. Dickstein and Leibenluft take a different tack, examining emotional dysregulation in bipolar, ADHD, and normal children from the vantage points of experimental psychopathology paradigms and functional magnetic resonance imaging (fMRI). Chang, Adleman, Wagner, Barnea-Goraly, and Garrett address the gradually emerging technology of fMRI as a means of distinguishing bipolar children from healthy children. Although there is no definitive biological marker for $\mathrm{BD}$, investigators are beginning to identify how brain function and structure, as revealed by fMRI, change at different phases of the development of BD.

Harvey, Mullin, and Hinshaw examine the role of sleep and wake rhythms in BD. Sleep has long been hypothesized to be a major contributor to mood shifts, although the cause/ effect relation between moods and sleep cycles is still unclear. On the stress side of the equation, Johnson and McMurrich discuss the significant literature on life events, and the 
mechanisms by which life events act as provoking agents in the cycling of pediatric and adult BDs. Post and Leverich provide an overarching framework that explains the interactive roles of stress, neurodegenerative changes, and mood disorder recurrences over time, and the potentially protective role of early intervention or prevention in altering this developmental trajectory.

A fourth theme is treatment. The mainstay of treatment for BD across the life span is still pharmacotherapy. Rather than simply summarizing the extensive pharmacotherapy literature, Thase discusses the real unmet need of persons with BD: how to get control over the unremitting and highly recurrent depressive phases of the illness, and the various agents (lithium, anticonvulsants, atypical antipsychotics, and antidepressants) that currently do and do not have supportive data. Delbello and Kowatch focus more extensively on children and the complexities of treating manic and depressive phases, especially when there are numerous comorbidities involved. The reader will be surprised at the extent to which pharmacological agents currently in wide use often lack data supporting their effectiveness.

Three new forms of psychosocial treatment are discussed. Miklowitz, Biuckians, and Richards discuss family-focused treatment, an established psychosocial intervention for adult bipolar illness (Miklowitz, George, Richards, Simoneau, \& Suddath, 2003), as an adjunct to pharmacotherapy in adolescent bipolar patients. Hlastala and Frank describe their beginning work on applying interpersonal and social rhythm therapy to teen patients. Both of these models were originally developed for adults, and the developmental adaptations the model required for younger patients will be of considerable interest to this readership. Finally, Fristad presents her group's data on multifamily and individual family psychoeducation groups for school-aged bipolar children. The reader will note the similarities and differences in psychosocial approaches depending on age group, theoretical orientation, and whether the family is involved in treatment.

It is our hope that this Special Issue will give the reader a sense of how much progress has been made in the developmental psychopathology and treatment of BD. It will also raise as many questions as it answers. Despite the exciting progress that has occurred, there is a great deal to be accomplished in advancing an integrative life span developmental understanding of $\mathrm{BD}$. The developmental questions raised in this Special Issue make clear that progress toward a process-level comprehension of BD will necessitate the implementation of research designs that incorporate multiple domains of variables within and outside the individual over developmental time. We believe that the most pressing and critical research questions are those that can be answered only in the broader context of theoretically informed variables, within and outside the individual who has, or is at-risk for, bipolar illness, especially as these variables change and influence one another over the course of development. We believe that not only will a more sophisticated and comprehensive understanding of adaptation and maladaptation in individuals with BD ensue, but also that this "multiple levels of analysis" perspective (Cicchetti \& Blender, 2004; Cicchetti \& Dawson, 2002; Miklowitz, 2004) will facilitate the translation of knowledge into developing interventions that prevent and ameliorate psychopathology. Such an interdisciplinary, multiple levels of analysis approach has the potential to become the guiding light for the next generation of studies on BD.

\section{References}

Cicchetti, D. (1993). Developmental psychopathology: Reactions, reflections, projections. Developmental Review, 13, 471-502.

Cicchetti, D. (2006). Development and psychopathology. In D. Cicchetti \& D. J. Cohen (Eds.), Developmental psychopathology: Theory and method (2nd ed., Vol. 1, pp. 1-23). New York: Wiley.

Cicchetti, D., \& Blender, J. A. (2004). A multiple-levelsof-analysis approach to the study of developmental processes in maltreated children. Proceedings of 
the National Academy of Sciences USA, 101, 17325-17326.

Cicchetti, D., \& Dawson, G. (Eds.). (2002). Special issue: Multiple levels of analysis. Development and Psychopathology, 14, 417-666.

Cicchetti, D., \& Rogosch, F. A. (2002). A developmental psychopathology perspective on adolescence. Journal of Consulting and Clinical Psychology, 70, 6-20.

Cicchetti, D., \& Toth, S. L. (1995). Developmental psychopathology and disorders of affect. In D. Cicchetti \& D. J. Cohen (Eds.), Developmental psychopathology: Risk, disorder, and adaptation (Vol. 2, pp. 369420). New York: Wiley.

Geller, B., Craney, J. L., Bolhofner, K., Nickelsburg, M. J., Williams, M., \& Zimerman, B. (2002). Two-year prospective follow-up of children with a prepubertal and early adolescent bipolar disorder phenotype. American Journal of Psychiatry, 159, 927-933.

Kleinman, L., Lowin, A., Flood, E., Gandhi, G., Edgell, E., \& Revicki, D. (2003). Costs of bipolar disorder. Pharmacoeconomics, 21, 601-622.

Leibenluft, E., Charney, D. S., Towbin, K. E., Bhangoo, R. K., \& Pine, D. S. (2003). Defining clinical phenotypes of juvenile mania. American Journal of Psychiatry, 160, 430-437.

Leverich, G. S., Altshuler, L. L., Frye, M. A., Suppes, T., Keck, P. E. J., McElroy, S. L., et al. (2003). Factors associated with suicide attempts in 648 patients with bipolar disorder in the Stanley Foundation Bipolar Network. Journal of Clinical Psychiatry, 64, 506-515.

Leverich, G. S., McElroy, S. L., Suppes, T., Keck, P. E. J., Denicoff, K. D., Nolen, W. A., et al. (2002). Early physical and sexual abuse associated with an adverse course of bipolar illness. Biological Psychiatry, 51, 288-297.

McClellan, J. (2005). Commentary: Treatment guidelines for child and adolescent bipolar disorder. Journal of the American Academy of Child and Adolescent Psychiatry, 44, 236-239.

Miklowitz, D. J. (2004). The role of family systems in severe and recurrent psychiatric disorders: A developmental psychopathology view. Development and Psychopathology, 16, 667-688.

Miklowitz, D. J., George, E. L., Axelson, D. A., Kim, E. Y., Birmaher, B., Schneck, C., et al. (2004). Familyfocused treatment for adolescents with bipolar disorder. Journal of Affective Disorders, 82(Suppl. 1), 113-128.

Miklowitz, D. J., George, E. L., Richards, J.A., Simoneau, T. L., \& Suddath, R. L. (2003). A randomized study of family-focused psychoeducation and pharmacotherapy in the outpatient management of bipolar disorder. Archives of General Psychiatry, 60, 904-912.

Murray, C. J. L., \& Lopez, A. D. (1996). The global burden of disease: A comprehensive assessment of mortality and disability from diseases, injuries, and risk factors in 1990 and projected to 2020. Boston: Harvard University Press.

NIMH. (2001). Research roundtable on prepubertal bipolar disorder. Journal of the American Academy of Child and Adolescent Psychiatry, 40, 871-878.

Perlis, R. H., Miyahara, S., Marangell, L. B., Wisniewski, S. R., Ostacher, M., DelBello, M. P., et al. (2004). Long-term implications of early onset in bipolar disorder: Data from the first 1000 participants in the Systematic Treatment Enhancement Program for Bipolar Disorder (STEP-BD). Biological Psychiatry, 55, 875-881.

Post, R., \& Kowatch, R. A. (2006). The health care crisis of childhood-onset bipolar illness: Some recommendations for its amelioration. Journal of Clinical Psychiatry, 67, 115-125. 